\title{
Creating cosmopolitan subjects - the role of families and private schools in
} England.

\section{Abstract:}

This paper examines the ways in which cosmopolitanism is imagined and planned for by 91 young women attending four private (elite) schools in one area of England. Despite many study participants coming from families where parents travelled internationally for business, few had a strong desire to reproduce such orientations in their own futures. The elite schools attended moreover placed relatively little emphasis on cosmopolitanism and transnationally mobile futures. For the few English young women doing the International Baccalaureate and/or actively considering higher education abroad, the decision to do so was driven by individual rather than family or social ambitions. Through our analysis we consider further whether cosmopolitanism is a form of (cultural) capital or a quality more embedded within the girls' habitus. The relatively ambivalent attitude to cosmopolitanism found in study schools ties to an ethnocentrism, which sees an 'English education' as among the most prestigious in the world.

\section{Introduction}

Education is posited as central to future trajectories in terms of securing or extending social class position and remaining competitive in a globalised economy. In this 'global war for talent' (Brown et al., 2011: 9), educational qualifications and other kinds of 'hard' credentials are a necessary part of what individuals must offer to potential employers. Increasingly, however, 'soft' currencies of employability - 'communication skills, persuasiveness, drive, resilience, adaptability, self-confidence, and problem-solving skills' (Brown et al., 2014: 3) are also being sought out, and used to distinguish the most talented from others within the widening pool of university-educated young people wishing to enter the labour market. One such 'soft' currency is a cosmopolitan sensibility and a willingness to be, or the experience of being, transnationally mobile. In this paper, we explore the extent to which cosmopolitanism is made possible, expressed and developed by a group of upper-middle class and elite young women, their families and the private schools they attended in one part of England. In doing 
Maxwell, C. \& Aggleton, P. (in press) Creating cosmopolitan subjects - the role of families and private schools in England. Sociology.

so, we are also able to begin considering when cosmopolitanism might best be conceived of as a form of (cultural) capital or whether at times it appears to be more productive to think of it as possibility becoming integrated into the habitus.

Recent comparative research by Power et al. (2013) on the employment aspirations of students attending elite universities - Oxford, in England and Sciences Po, in France - argues that English graduates are more likely to perceive transnational mobility as integral to their future work biography than their French counterparts. The authors conclude that in many ways English elite students epitomize 'the nomadic worker of the transnational elite' (p. 578). An earlier study by Reay and colleagues (2007), examining the reasons why white middle class parents may choose to send their children to under-performing urban state schools, found that one of the main factors informing this decision was the 'value-added' for their children who would thereby become 'globally knowledgeable, tolerant, inclusive young white middle-class individuals who are better prepared for a global economy' through their encounters with the ethnic 'Other' (p. 1052). Both of these studies suggest that privileged groups in English society are globally-focused and aware that a cosmopolitan outlook and orientation will support them in their futures.

The force with which transnational mobility and cosmopolitanism is claimed as being essential to secure a competitive advantage in the labour market is driving families, schools and universities to provide such opportunities - through families moving abroad or sending their children abroad for secondary or tertiary education (Rizvi, 2005; Waters, 2008; Kenway and Fahey, 2014); through families choosing 'international schools' (Brown and Lauder, 2011; Resnik, 2012) or international qualifications such as the International Baccalaureate (Doherty et al., 2012); through schools linking with other similar types globally (Rizvi, 2014); through exchange programmes, especially in higher education (Findlay et al., 2012; van Zanten and Maxwell, 2015); and through community service activities in Southern or developing world contexts (Allan and Charles, 2014; Howard, 2014).

Much literature argues that rather than these experiences of mobility and encounters with the Other developing within young people a desire for 'global solidarity' (Rizvi, 2005), such opportunities are viewed largely more strategically - as a way of distinguishing the self from others in a competitive, global marketplace (Findlay et al., 2012; Igarashi and Saito, 2014) thereby further embedding and extending inequity and inequality (Igarashi and Saito, 2014). 
Maxwell, C. \& Aggleton, P. (in press) Creating cosmopolitan subjects - the role of families and private schools in England. Sociology.

With specific reference to research on privileged, young English people, studies by Snee (2013), Maxwell and Aggleton (2013), and Allan and Charles (2014), among others, have found that time spent abroad is often driven by individualised motivations for self-fulfilment (Power et al., 2013) and drawn on during processes of cultural distinction (Bourdieu, 1984). The exchange-value (Skeggs, 2004) of the accumulation of such experiences is emphasised, rather than a shift in the way young people understand themselves and others - through 'global reflexivity' (Savage et al., 2005: 181) or the ability to draw on global (rather than local or national) frames of reference when making sense of their experiences.

For the purposes of this paper we understand 'cosmopolitanism' as implying an openness, interest and ease of engagement with the Other - in the form of exotic/foreign cultures, places and people (Snee, 2013). The notion suggests an international- and open-mindedness, but also greater flexibility in the way one thinks (Hayden et al., 2000). Giddens (1991) has suggested a cosmopolitan person typically feels at ease across a wide variety of contexts something Gaztambide-Fernández (2009a) argues is a crucial skill developed by the elite students he studied in the USA - and that cosmopolitans makes use of this fluidity to develop distinctive self-identities. Thus, linked to cosmopolitanism is being transnationally mobile and not necessarily seeing oneself as anchored to one location.

Behind much recent literature defining cosmopolitanism as a concept, are broader debates within this 'recognizable field of sociological inquiry' (Igarashi and Saito, 2014: 223). In particular, is cosmopolitanism a form of cultural capital, a form of capital in its own right, or is it best understood as a set of practices linked to a ruling class (Rothkopf, 2009) or upwardly mobile (Brooks and Waters, 2011; Fahey, 2014) habitus?

Igarashi and Saito (2014) see cosmopolitanism as a form of cultural capital, embodied through 'dispositions of openness to foreign others and cultures and competencies to enact such openness with ease' (p. 225, emphasis in the original), objectified through the cultural products they consume and artefacts they own ('foreign' food and works of art), and institutionalised via educational qualifications gathered. They illustrate how other forms of capital can mediate the accumulation of cosmopolitanism: both economic, in terms of accessing international and elite forms of education and opportunities for travel; and social, through the networks people are part of. 
Maxwell, C. \& Aggleton, P. (in press) Creating cosmopolitan subjects - the role of families and private schools in England. Sociology.

Weenick (2008) and Bühlmann et al. (2013), on the other hand, argue for seeing cosmopolitanism as a specific form of capital. Weenick defines cosmopolitan capital as comprising 'bodily and mental predispositions and competencies (savoir faire) which help [individuals] to engage confidently in such arenas [the labour and educational markets]' (2008: 1092). Cosmopolitan capital can therefore be accumulated, displayed and activated/put into practice. Weenick (2008) emphasises that what is understood as legitimate cosmopolitan capital is determined by dominant social groups within the various local, national and global fields of power. Bühlmann et al. (2013) also considers the case for cosmopolitan capital and decide that in their research context - Swiss business elites - it is a heuristically useful device, especially as experience and knowledge of the international (as opposed to the national) context is critical in differentiating who becomes part of the elite within the Swiss banking world.

However, the emphasis placed on dispositions and competences by both Weenick (2008) and Igarashi and Saito (2014) opens up the possibility of thinking about cosmopolitanism as being integrated within the habitus for some. If parents inculcating an engagement with global frames of reference are themselves transnationally mobile and possibly untethered to a particular nation state, as some of the global middle classes (Ball, 2010; Ball and Nikita, 2014) or the global power elites (Rothkopf, 2009) are argued to be, perhaps cosmopolitanism shapes practices more deeply. While always fluid and being re-worked, some actors may develop a predisposition to view the world through the lens of cosmopolitanism, rather than accumulating and activating cosmopolitanism as a form of (cultural) capital. This more embedded approach to cosmopolitanism, understood as part of a particular class fraction's habitus, allows for a focus on the more flexible forms of subjecthood adapted to emerging capitalist demands in a global field of power (as suggested by Ong, 1999) and linked to specific forms of global citizenship. Thinking about cosmopolitanism as embedded within the habitus of certain classes or class fractions shifts our understanding of the term from a resource that is collected and used strategically, to a conceptualisation of cosmopolitanism as more deeply ingrained in the practices and identity narratives of specific subjects in the context of globalisation.

Given that research has argued that more privileged and well-resourced groups are more likely to pursue and be successful in their aim of gathering the international educational qualifications, soft skills and cosmopolitan experiences demanded by employers in the global 
Maxwell, C. \& Aggleton, P. (in press) Creating cosmopolitan subjects - the role of families and private schools in England. Sociology.

labour market today, we want to consider the case of young women being educated in four private (elite) schools in England in order to examine how cosmopolitanism is understood and made possible within this context. This will potentially allow us to contribute to broader debates about the nature of cosmopolitanism, but also to understandings of the ways in which it is promoted and made possible through the institutions of the family and schooling (Brown et al., 2014).

\section{The study}

The data drawn on in this paper come from a three-year study of 91 young women, aged 1418 years, attending four private schools in one part of England. The main purpose of the research was to understand how these young women engage in practices that are agentic, and the ways in which these practices may be reproductive of various forms of privilege. Participants shared in common the fact that their families' had the ability to pay for an expensive and exclusive education (only seven per cent of students in England are privately educated - Dearden et al., 2010). Even for those students who were attending these institutions on a bursary/scholarship, their immersion in such a privileged space suggests they and their parents expect a future trajectory that will secure for them certain forms of advantage.

Of the four schools in the sample - two were single-sex schools and the other two coeducational and, within each of these groupings, one was a day school while the other was a boarding school. One school is known nationally for its success in examination results and two others for their provision of a 'traditional public school education' - both of which have been argued to be indicators of elite schooling (Gaztambide-Fernández, 2009b; Kenway et al., 2013). All young women in Years 10-13 (i.e. between the ages of 14 and 18years) were invited to participate across the four schools. This paper draws on 147 interviews conducted with young women (91 first interviews, and 56 with participants who agreed to a second interview 12-24 months later).

The interviews were presented to young women as wishing to explore why they were attending their particular school, how they experienced their education, their relationships with family and peers, and aspirations for the future. Although the examination of cosmopolitan capital or dispositions was not an explicit focus of the broader study, to inform the writing of this paper, we returned to all our interview narratives and considered what 
Maxwell, C. \& Aggleton, P. (in press) Creating cosmopolitan subjects - the role of families and private schools in England. Sociology.

experiences of transnational mobility, overseas travel, orientations to encounters with the Other, young women discussed when talking about their family histories and current circumstances, their trajectories into the particular secondary school they were attending, holidays they had enjoyed, community service they had engaged in, and their aspirations for the future. Drawing on a framework suggested by Rizvi (2005) and Findlay et al. (2006), and building on our own work that emphasises the need to examine how family histories and resources, as well as school orientations interact with 'projects of the self' to determine life orientations and practices (Maxwell and Aggleton, 2014b), we consider here the ways in which cosmopolitanism and transnational mobility were being imagined and planned for by young women based on their family and own experiences, and then the ways in which the schools were promoting cosmopolitan sensibilities and opportunities. Such an analysis will support further reflection on whether and how cosmopolitanism is interpreted and 'used' (Rizvi, 2005) by members of this group.

\section{Imagining a cosmopolitan future}

For some young women, the possibility of a cosmopolitan future had been opened up by parents who travelled the world for business or who owned properties in other countries. Beyond this, there were girls who had lived abroad because of their parents' employment, or had parents who were born abroad and were not UK nationals.

\section{Experience of travel and living abroad}

Charlie (15 years old, St. George's School, coeducational boarding school) provides one example of a young woman whose family was fairly mobile in the sense of travelling abroad regularly for work and leisure. Her father owned a company, which meant he ended up 'travelling a lot to the Far East ... [he has] loads of offices over there'. Her family also owned a house in Spain where they holidayed often. However, when discussing her own future, Charlie did not talk about wanting to work outside England or running her own business. Similarly. Anna (14 years old, also at St. George's) came from a family that owned homes in various countries. Despite a childhood spent travelling around abroad (though she had always been educated in England), Anna emphasised that when she herself had children she would ensure they had only one home, with parents who travelled less. 
Maxwell, C. \& Aggleton, P. (in press) Creating cosmopolitan subjects - the role of families and private schools in England. Sociology.

'If I ever had kids or like settled down with a husband, I just generally would much want to prefer to be in one space and like you'd have one home. 'Cos you get so much sometimes ... like you can never really call a place home. ...'

This suggests the utilisation of a local rather than a cosmopolitan frame of reference by these young women at this point in their trajectories, a trend mirrored by the majority of our participants.

In contrast, approximately one quarter of the young women in the study articulated the benefits they saw of experiencing the world beyond the shores of England, and expressed the desire to pursue more mobile trajectories in the future through travel for pleasure, university education or work. One factor that appeared to shape such future imaginaries was the experience of having lived abroad. Jenny and Lara, for instance, spoke of how these experiences distinguished them from their peers..

Jenny (16 years old, Brownstone School, coeducational day school) had spent much of her childhood in the Middle East, because of her father's job. The family had returned to England, in part so that Jenny could complete her education there. Jenny explained that she had a different perspective to many of her peers - 'I feel more developed in a way as a person, you know I've seen a lot of the world and I understand it maybe in ways that other people don't'. She continued,

'Certainly in the future I'd love to see more of the world and, you know, keep that part of life up. But I think growing up in a different country, I'm not sure whether I'd say in the future when I have children of my own whether I'd want them to - that's quite difficult for me to say - but I would certainly want them to be quite well travelled and understanding of different cultures, because I think having had that, I can see how important it is.

It is possible to see here how Jenny's previous experiences informed her interest in travel and an understanding of herself as 'different' because she had a more global outlook and frame of reference. She talked about wanting her children to have a similar cosmopolitan sensibility, and yet, was unwilling to commit to seeking a future for herself that would be transnationally mobile (beyond travel for leisure), despite her overall assessment that growing up abroad had been beneficial to herself:

'One of my English teachers is the same sort of as me, she grew up in a different country and then moved back ... And sometimes when we're sitting studying 
Maxwell, C. \& Aggleton, P. (in press) Creating cosmopolitan subjects - the role of families and private schools in England. Sociology.

different poems or whatever it was, then something would come up and we would understand it and none of the rest of the class would get their heads around it'.

In such an articulation of how experience of the Other may shape understandings, we can see the utilisation of a narrative that draws on practices of distinction, but also one which suggests that a different, more global frame of reference is being drawn on - in this case to aid the appreciation of a poem. Might this be an indication of Jenny having a more cosmopolitan habitus?

When she was ten years old, Lara's (16 years old, Abbey Mill School, single-sex boarding school) family had also relocated to the Middle East. However, she had only spent one term at an international school there (a sister school to a premier private school in England) before returning to England to complete her primary education at the institution she had previously attended - this time as a boarder. Her parents had always intended her to receive her secondary schooling in England, so they thought it wise that she continue in the same system. However, Lara spent most of her holidays in the Middle East and joined a large group of friends whose families were based there, but returned to England for their education. When asked whether she might want to live abroad after university, Lara replied:

'I don't know, yeah. I think I'm really glad it was when I'm younger because (inaudible) thinking about it, it's been an amazing experience, because I've had ... I've seen both of what like ... I've kind of got the best of two worlds ... But yeah, I think it's made me think ... cos like before I never even thought about going international (inaudible) but now I certainly think a lot more about it'.

For Lara, the experience of her parents' transnational mobility and of having a group of friends in a similar position, called forth the possibility of a global future, although, once again, like Jenny, she seemed unwilling to commit herself entirely to such a path.

Furthermore, Lara's experience in the Middle East had been far briefer as she had returned swiftly to England for her education. In part, Jenny and Lara's parents' emphasis on receiving an English education in England had the effect of limiting these young women's sense of transnationality, yet Jenny's articulation of how growing up abroad had shaped her is relevant to a consideration of whether cosmopolitanism is a form of (cultural) capital or something that is can become more integrated into the habitus.

Studying and living abroad in the future 
Maxwell, C. \& Aggleton, P. (in press) Creating cosmopolitan subjects - the role of families and private schools in England. Sociology.

Only one fifth of young women in the whole sample actively discussed wanting to study or live abroad. Young women were more likely to talk about the former, perhaps because higher education decisions were those they were most concerned about at this particular phase of their lives. Georgina (15 years old, Osler School - single-sex day school) and Allie (16 years old, Abbey Mill School - single-sex boarding school) both expressed an interest in applying to study at a US Ivy League university. However, their interests were closely tied to representations of themselves as academically extraordinary and highly ambitious, rather than the desire to become cosmopolitan. Additionally, Allie's father was based in the USA, so she was keen to be closer to him.

Amelia (14 years old, Abbey Mill - single-sex boarding school) also wanted to study at a US university. She explained that her mother had a degree from Oxford, her father had been educated at Cambridge, and her brother had his sights set on his father's alma mater, so one way of understanding Amelia's narrative about wishing to study in the USA was in terms of a desire to differentiate herself from the rest of her high-achieving family who had arguably achieved the highest academic accolades possible in a UK context. However, Amelia explained her parents were not supportive of the idea because it might mean she would stay abroad longer-term:

'I really want to go to an American university ... But my parents don't really want me to because then you know if I like get married while I'm in America or something, then I'll kind of be way far away. ... So they don't want that. But ... I don't know, I really want to go to an American university 'cos they're just ... I don't know, just getting out of England. And all the English universities, I mean they're lovely, but they're all sort of so English and ... English and old and great, and it's kind of like I want to go to an American university, have fun'.

While Amelia may have expressed a desire to move away from England because a US higher education would be more modern and 'fun', her interview did not necessarily suggest a passion for cosmopolitanism or that such a choice might relate to personal preparation for a transnational future.

Only two young women actively talked about wanting to live abroad. Georgia (17 years old, Abbey Mill School, single-sex boarding school) said, within the first few moments of the interview, 'I don't want to live in England when I was older, so might as well get out soon...' Georgia explained that her father had been in the Army, and after that had run a company organising expeditions: 
Maxwell, C. \& Aggleton, P. (in press) Creating cosmopolitan subjects - the role of families and private schools in England. Sociology.

'... because my dad's always been travelling, so he's always encouraged me to travel. And then since ... I've loved it since obviously a young age and so they kind of realised that I wouldn't really live in England so ...'

Georgia was planning to apply to university in the Netherlands and then continue her development as an artist in other cities in Europe. Georgia suggested that her father's mobility in his work had inspired her to see her own future in the same way. Sasha (18 years old, Brownstone, coeducational day school) positioned herself as a 'global traveller' with a passion for traveling, and was keen not to stay in one place for too long:

'When [my mum] broke up with my dad, we just spent a lot of time travelling, a lot of time moving, a lot of time like 'I'm sick of this place, let's move' and we did. So um ... I've seen lots of places, lots of cultures, so that's been incredible. I don't think I could stop doing that'.

Sasha presented her biography as one of mobility and cosmopolitanism. She explained that she was planning to study anthropology at university and then wanted to keep travelling in the future. Both Sasha's and Georgia's narratives suggest a desire to look beyond the national in order to find a place in the world and a social space that best suited them. However, these young women were the exceptions rather than the norm in our sample, despite the fact that many others had the family resources to enable them to travel for holidays, or had parents who spent much of their time abroad on business.

\section{Being different already}

There was however another group of young women in our study that also had strong connections outside England and might therefore have been encouraged to develop a more cosmopolitan disposition - those whose parents were overseas nationals, but were resident in England. Sophia, Kristina, Bella (from St. George's - coeducational boarding school), Mary (Brownstone - coeducational day school), Christie (Osler - single-sex day school) and Hana (Abbey Mill - single-sex boarding school) all had at least one parent who had been born abroad. Only Bella, Mary and Christie had experience of living abroad, with Bella's parents now being based in her mother's home country (France). Theoretically, these young women might have been expected to have a more cosmopolitan outlook as a result of their mixed heritage and their experience of other cultural practices. For all the young women, except perhaps Christie, the effect of their Otherness was most clearly expressed in terms of them feeling less integrated into the peer networks at their schools. For Hana, Sophia and Kristina 
Maxwell, C. \& Aggleton, P. (in press) Creating cosmopolitan subjects - the role of families and private schools in England. Sociology.

this seemed linked to their families having fewer economic resources and a sense of needing to achieve academically to 'pay-back' the scholarships they had been offered (Sophia and Hana), or to the significant financial sacrifices their parents had made (Kristina).

While Mary (in her first interview, 17 years old) stressed her love of travel - 'every school holiday I try to get away ... this summer I'm hoping to go Inter-Railing or maybe even rent an apartment for a month in a different country, so in Asia, and live there for a month', and her desire to study in her mother's home country because 'I want to live in Norway at some point in my life, I want to learn Norwegian desperately', when we re-interviewed her 15 months later, she had decided to stay on in England for her university education. Mary explained that although her motivation to study in her mother's home country had been driven by the desire to 'develop' that side of herself and strengthen her relationship with her maternal grandmother by speaking the national language fluently - she had decided that undertaking undergraduate education in a second language would be very challenging. Choosing England was an 'easier transition'. However, Mary emphasised that she was still considering doing a Masters degree in Norway, where postgraduate programmes are typically taught in English.

Bella (15 years old), who had grown up in her mother's home country (France) and lived there until age 13, had come to England initially because of the difficulties she had experienced with peer relationships in her previous state school abroad. Her parents also thought that learning to speak English (her father's mother tongue) fluently would be an advantage. After some deliberation, the decision had been made that she would stay in England to complete her schooling, as returning to her home country would likely necessitate she re-take a year. However, Bella remained undecided about whether she would go to university in the UK or elsewhere in Europe. For both Mary and Bella, the possibility of studying abroad and planning a future outside England had been opened up as a result of their connections to their mothers' home countries, and both young women clearly expressed an affiliation with, and a desire to see themselves as not only English.

Overall, what was particularly interesting about this group of young women was that they did not emphasise their Otherness as necessarily conferring an advantage, or acting as a resource on which they could usefully draw, in the manner that the notion of cosmopolitanism being a form of (cultural) capital suggests. In accounting for this, it may be that the English private 
Maxwell, C. \& Aggleton, P. (in press) Creating cosmopolitan subjects - the role of families and private schools in England. Sociology.

school in which they found themselves did not seek to celebrate such forms of Otherness as having significant value in today's world. We explore further below why that might have been the case.

\section{Preparing and producing cosmopolitan students}

In what ways did the four schools involved in our study facilitate the development of imaginations of transnational mobility and cosmopolitan futures, and seek to forge trajectories that might put such potential futures in place?

In recent work, Allan and Charles (2014) and Brooks and Waters (2014) have emphasised how elite schools offer travel opportunities to their students - especially through charitable work. In our sample, Abbey Mill, a traditional boarding schools for girls, is perhaps closest to the historically elite girls schools described in Allan and Charles (2014) and by Epstein (2014), in which international service is valorised as the legacy of one of the schools' founding principles. Abbey Mill actively runs its own international charity venture - raising money for partner schools in developing countries and sending groups of students to visit these. The deputy head teacher explained that this work aimed to make students 'face their own prejudice', but that the driver for this work was the school, not necessarily the parent community - 'most of our parents would happily never have [their daughters] exposed to anybody who is slightly different to them'.

At Brownstone, in contrast, while this coeducational day school offered opportunities for travel and service work, it did this through a third party organisation, World Challenge, whose focus was on: 'acclimatisation, trekking, project, and rest \& relaxation'. At St. George's School, a large commemorative book on this coeducational boarding school's past and present aimed at school alumni and prospective parents, did not highlight opportunities for international travel or service work as part of the education offered. Additionally, only one international charitable undertaking is listed on their school website, alongside entries relating to more locally-oriented community work. Thus, it seems somewhat unlikely that a global orientation of the kind described by Ong's (1999) 'transnationality' or Savage et al.'s (2005) 'global reflexivity', would be made possible through opportunities for international service offered by the schools. 
Maxwell, C. \& Aggleton, P. (in press) Creating cosmopolitan subjects - the role of families and private schools in England. Sociology.

To what extent were schools, therefore, able to offer other opportunities for imagining and planning for cosmopolitan futures? Drawing on Doherty et al. (2012) and Brooks and Waters (2014), we consider the possibilities for cosmopolitanism opened up through the provision of the International Baccalaureate (IB) and the promotion of university education abroad. Of the four schools in our study, only St. George's (coeducational boarding school) offered the IB and the vast majority of students taking this qualification were overseas students - from Europe and Asia. Of the two young women in our sample studying for the IB at St. George's who were not overseas students - Sophia and Tallulah (both aged 17 years at the time of their first interview) were academic scholars, with their sights set on Oxford or Cambridge universities respectively. Sophia's parents had been brought up abroad, although they had come to England for work, while Tallulah came from a family whose father held a senior public position requiring him to work at an international level with fellow professionals from around the world. When she was interviewed for the second time, Sophia was planning to do her second year of her university degree course abroad, while Tallulah was already on her way to China for a year, as part of her university course. These two young women may be the kinds of subjects most likely to become 'the nomadic worker of the transnational elite' (Power et al., 2013: 578). First, they came from families that have the cultural resources that make possible the imagination of a cosmopolitan future (although in Sophia and Tallulah's case these were quite different). Second, they were two of the highest academic achievers in their year at school and had made the 'choice' to take what was perceived to be a harder qualification route (the IB). Consequently, both young women had headed off to elite universities, where they had been encouraged or expected to spend time studying abroad.

The promotion of an Ivy League over a Russell Group [considered to be the top tier British universities] or Oxbridge [Oxford and Cambridge] university education, could be a further way in which elite schools make possible a transnational future. However, only a small number of young women actively mentioned such a desire. While at McCarthy et al. (2014)'s elite school, the Barbadian Argonauts were being actively pursued by Ivy League universities and were themselves keen to look to North America for their future, aspirations for Ivy League university admission in our study schools appeared to be driven more by individuals themselves rather than by the schools. Of the four schools studied here, only St. George's and Osler's websites mentioned they had expertise in advising their students on applying to non-UK universities, but little more is said about this, the focus being instead on 
Maxwell, C. \& Aggleton, P. (in press) Creating cosmopolitan subjects - the role of families and private schools in England. Sociology.

how young people will be guided through the UCAS system (the application system for UK universities).

From the above analysis, it would appear as if the ways in which the schools in this study are creating possibilities for imagining a cosmopolitan future and planning, or putting into place strategies for encouraging transnational mobility, are fairly limited. If schools are not actively engaged in such forms of work, it is difficult to argue that they are cultivating or activating forms of (cultural) capital linked to cosmopolitanism.

So far, we have sought to highlight where possibilities for cosmopolitan dispositions may arise for these elite school students, while illustrating the strong Anglo-centric focus of many of the families, schools and individual young women. Just as in Fahey's (2014) analysis of the Asian young women attending Highbury Hall (as pseudonym), another elite boarding school in England, it was the overseas, foreign national students who appeared to be developing the most cosmopolitan outlook for the future. Of the two boarding schools in our study, only one - St. George's - had a large minority of overseas nationals studying there. This group (although they consisted of a relatively diverse group of young people - from the East Asia as well as Eastern and Western Europe) was relatively isolated from the English students and spent much of their time together. Ellie (16 years old) had joined the school for the final two years of her secondary schooling to complete the IB. All of her friends were overseas students, 'British people, they're quite ... I don't want to say snobby, but it's like they're kind of looking down on you. I was like, 'Sorry, I'm just new in this country, you could be a bit nicer' (laughs) 'more welcoming'. She compared St. George's to the English private school her brother had attended where 50-70 per cent of students came from overseas, but concluded that despite the relative disinterest shown by her UK peers towards her, perhaps a St. George's education was preferable as 'now I actually appreciate it that I get like pure English, English ... like British English' language acculturation. When Ellie was interviewed for the second time, four months before she was to finish her formal schooling, she appeared more integrated into the school, but was still mainly involved within the small student group doing the IB. She had decided to return to her home country (Germany) for her university education, having failed to be offered a place by the University of Cambridge. With strong friendships having been formed with peers from all over Europe and parts of Asia while at St. George's, she described a future set of social relationships that had the 
Maxwell, C. \& Aggleton, P. (in press) Creating cosmopolitan subjects - the role of families and private schools in England. Sociology.

potential to take her around the world, and an understanding of a range of cultural outlooks not mentioned by other young women in our study.

However, the extent to which the recruitment of a diverse student population by elite (boarding) schools such as St. George's and Abbey Mill foster friendships and long-term networks between young people from across the globe may be limited if, as Brooks and Waters (2014) argue, a focus on internationalism (including the recruitment of overseas students) is only present when 'considered commercially productive' (p.14). This chimes with our own reading of the position of overseas students in the two boarding schools in our research, starkly illustrated in the quotation that follows. Abbey Mill (single-sex boarding school) had a much less visible overseas student population; in fact we did not encounter any such students during the entire time we spent at the school. During her second interview, which took place after she had left the school, Eliza (18 years old at the time) explained that her younger sister was not going to follow her to Abbey Mill because it had changed:

'The reasons that I went [to Abbey Mill] was because it was a rural, countrified all girls' boarding school that had traditional values ... I mean teachers still had dogs in lessons ... there wasn't the whole competitive drive, there was no push. ... And then by the time that I left there was far more non-gentlemen ... lots lots more foreign people ... I mean we had Chinese girls coming in by the end. I mean we hardly knew what a Chinese girl looked like when I started.'

With such strong sentiments being expressed by local families about overseas students diluting the 'Englishness' of the education their own children would receive, schools will need to carefully balance the economic imperative to extend their clientele base with recruiting the 'right' overall demographic profile for the school (see also Kenway et al., 2015). Given the push towards ethnocentrism expressed by Eliza here, the kinds of elite schools we have studied may find it difficult to promote and embrace cosmopolitan orientations that create the kind of nomadic elite worker called forth by Power et al. (2013), or the potential for transnationality discussed by Ong in Fahey (2014) through which flexible, global citizen subjects may be formed.

\section{Conclusions}

Drawing on the narratives of 91 young women attending four private (elite) schools in one area of England, we have sought to examine whether and how young women's experiences within their families and through the provision in their schools, engage with the idea of 
Maxwell, C. \& Aggleton, P. (in press) Creating cosmopolitan subjects - the role of families and private schools in England. Sociology.

cosmopolitanism. Such a focus on cosmopolitanism allows us to tentatively add to debates about whether or not cosmopolitanism is best viewed as a form of cultural capital, a type of capital in its own right, or whether it is a disposition that has the potential to become seamlessly and unconsciously integrated into elements of habitus - a key question within the sociology of cosmopolitanism.

Although a number of the young women interviewed were destined for Oxford, Cambridge and other elite higher education institutions, very few displayed the dispositions characteristic of Power et al.'s (2013) nomadic, transnational elite worker. Many informants in this study had travelled extensively and had experience of holidaying abroad, staying in properties owned by their families in various parts of the world, but only a few talked about transnational mobility as a central part of their future trajectories. It may be that as schoolage young people, they were still too young to imagine such futures - but this seems unlikely when many had parents who had travelled extensively for work and interviewees reported being pushed by their schools to decide what subjects to specialise in, with concomitant implications for university degree choices and ultimately their career trajectories from as young as 14 years.

For those few study participants who expressed a wish to study abroad, their narratives appeared to present this choice as part of a strategic process of acquiring a particular form of capital - with which they could distinguish themselves in the 'global war for talent' (Brown et al., 2011). Whether cosmopolitanism, in such a reading, should be understood as a form of cultural capital or as a capital in its own right depends to some extent on how this group of young women understand the value of such a sensibility - as just one of numerous 'soft skills' employers are seeking (i.e. as one aspect of cultural capital), or a very specific type of orientation and resource, increasingly valuable in the era of globalisation (a form of capital in its own right). Further research with this particular privileged group would be needed to examine this differentiation more closely.

However, our analysis allows us to suggest that for a very small group of young women (e.g. Jenny and Sasha in particular), who are part of this particular fraction of the English education system, experience of the Other (through travel or living abroad) provided them with new sensibilities - or ways of understanding situations through a different lens. Relatively extensive experience of international travel drove the desire to continue such a 
Maxwell, C. \& Aggleton, P. (in press) Creating cosmopolitan subjects - the role of families and private schools in England. Sociology.

journey - whether only for leisure, or possibly combined with work. It is in these latter narrations that cosmopolitanism could potentially be understood as having become embedded within the young women's habitus (rather than a more strategically deployed form of capital). The interesting interplay between the local and global in the narratives initially elicited in this study would ideally be further explored through the collection of data more specifically targeted at examining this question, which would in turn allow us to further contribute to, and extend this argument.

For other participants, experience of the Other and the possibility of developing a broader, more globally-reflexive sensibility was not articulated is so clearly a calculated way. This may be because it has already become more integrated as part of the habitus, but we must also understand these young women's narratives as formed by the taken-for-granted socioeconomic context in which they lived - where holiday homes abroad and extensive travelling were seen as somewhat normal. Crucially, however, it is also connected to a relatively assured and optimistic approach to their current and future practices (Maxwell and Aggleton, 2014a), whereby education and employment success are, to a large extent, assumed, although they still need to be worked at. These two factors, together with schools' hesitancy to promote cosmopolitanism as a strategic resource, may explain the lack of overt emphasis given to cosmopolitan futures in the accounts of the young women studied. As we have sought to highlight in our analysis, young women seemed to position themselves differently in relation to this question depending on their background and family experiences, and the affective forces shaping their current practices and imagined futures. Future efforts to examine privileged young people's narratives in relation to cosmopolitanism should therefore carefully consider how these three aspects (families, young women and schools) shape possibilities for the cultivation of cosmopolitanism as a form of (cultural) capital and/or how they facilitate the embedding of such an orientation into the habitus.

We want to conclude by emphasising a further point which may help to explain why cosmopolitanism was less overtly articulated by many of the young women in our study. Despite a globally-connected economy, with London viewed as one of the finance capitals of the world with a large, multicultural population (a global city - Sassen, 2012), the concept of an English, traditional public (i.e. private) school education is still held-up as an ideal to pursue (Brooks and Waters, 2014; McCarthy and Kenway, 2014; Sandgren, 2014). In our study, globally mobile parents appeared to view an English public school education as a 
Maxwell, C. \& Aggleton, P. (in press) Creating cosmopolitan subjects - the role of families and private schools in England. Sociology.

necessity for their own children, despite reputable international schools being available locally. Families and schools, on the whole, also viewed elite English higher education as providing the most desirable destination for their children, arguably reinforcing the ethnocentrism and value given to an education in which both schools and universities share a common vision of success (Stevens, 2009; Weis and Cipollone, 2013). In our study, the 'global imaginations' (Kenway and Fahey, 2014: 189) proffered by both families and elite schools remained limited, despite evidence of our living in an increasingly globallyconnected world with 'unprecedented levels of mobility' (Skrbis et al., 2014: 614). This is an interesting contradiction. Such ethnocentrism may be linked to the values and orientations of particular fractions within the upper middle- and upper classes who choose to educate their children in the English private sector, and who are either confident their children will inevitably succeed in the 'global war for talent' (Brown et al., 2011: 9) or fail to envisage a future for them beyond the boundaries of the UK.

Acknowledgements:

This work was supported by the UK Economic and Social Research Council under grant RES-062-23-2667.

\section{References}

Allan A and Charles C. (2014) Cosmo girls: Configurations of class and femininity in elite educational settings. British Journal of Sociology of Education 35: 333-352.

Ball S. (2010) Is There a Global Middle Class? The beginnings of a cosmopolitan sociology of education: A review. Journal of Comparative Education 69: 137-161.

Ball S and Nikita DP. (2014) The global middle class and school choice: A cosmopolitan sociology. Zeitschrift fuer Erziehungswissenschaft 17: 81-93.

Bourdieu P. (1984) Distinction, London: Routledge \& Kegan Paul.

Brown C and Lauder H. (2011) The political economy of international schools and social class formation. In: Bates R (ed) Schooling Internationally: Globalisation, internationalisation and the future for International Schools. London: Routledge, 39-58.

Brown P, Lauder H and Ashton D. (2011) The Global Auction: The broken promises of education, jobs and rewards, Oxford: Oxford University Press.

Brown P, Power S, Tholen G, et al. (2014) Credentials, talent and cultural capital: a comparative study of educational elites in England and France. British Journal of Sociology of Education.

BühImann F, David T and Mach A. (2013) Cosmopolitan Capital and the Internationalization of the Field of Business Elites: Evidence from the Swiss Case. Cultural Sociology 7: 211-229.

Dearden L, Ryan C and Sibieta L. (2010) What determines private school choice? A comparison between the UK and Australia. IFS Working Papers. 
Maxwell, C. \& Aggleton, P. (in press) Creating cosmopolitan subjects - the role of families and private schools in England. Sociology.

Doherty C, Luke A, Shield P, et al. (2012) Choosing your niche: The social ecology of the International Baccalaureate Diploma in Australia. International Studies in Sociology of Education 22: 311332.

Epstein D. (2014) Race-ing Class Ladies: Lineages of Privilege in an Elite South African School. Globalisation, Societies and Education 12: 244-261.

Fahey J. (2014) Privileged girls: the place of femininity and femininity in place. Globalisation, Societies and Education 12: 228-243.

Findlay AM, King R, Smith FM, et al. (2012) World class? An investigation of globalisation, difference and international student mobility. Transactions of the Institute of British Geographers 37: $118-131$.

Findlay AM, King R, Stam A, et al. (2006) Ever reluctant Europeans. The changing geographies of UK students studying and working abroad. European Urban and Regional Studies 13: 291-318.

Gaztambide-Fernández R. (2009a) The Best of the Best: Becoming elite at an American boarding school, Cambridge, MA: Harvard University Press.

Gaztambide-Fernández R. (2009b) What Is an Elite Boarding School? Review of Educational Research 79: 1090-1128.

Giddens A. (1991) Modernity and Self-Identity. Self and Society in the Late Modern Age, Cambridge: Polity.

Howard A, Polimeno A and Wheeler' B. (2014) Negotiating privilege and identity in educational contexts, New York: Routledge.

Igarashi H and Saito H. (2014) Cosmopolitanism as cultural capital: Exploring the intersection of globalization, education and stratification. Cultural Sociology 8: 222-239.

Kenway J and Fahey J. (2014) Staying ahead of the game: the globalising practices of elite schools. Globalisation, Societies and Education 12: 177-195.

Kenway J, Fahey J and Koh A. (2013) The libidinal economy of the globalising elite school market. In: Maxwell $\mathrm{C}$ and Aggleton P (eds) Privilege, Agency and Affect. Basingstoke: Palgrave Macmillan, 15-31.

Kenway J, Langmead D and Epstein D. (2015) Globalizing femininity in elite schools for girls: Some paradoxical failures of success. In: Zanten Av, Ball S and Darchy-Koechlin B (eds) Elites, privilege and excellence: The national and global redefinition of educational advantage. London: Routledge.

Maxwell C and Aggleton P. (2013) Becoming accomplished: Concerted cultivation among privately educated young women. Pedagogy, Culture \& Society 21: 75-93.

Maxwell C and Aggleton P. (2014a) Agentic practice and privileging orientations among privately educated young women. The Sociological Review 64: 800-820.

Maxwell C and Aggleton P. (2014b) The reproduction of privilege: Young women, the family and private education. International Studies in Sociology of Education 24: 189-209.

McCarthy C, Bulut E, Castro M, et al. (2014) The Argonauts of postcolonial modernity: elite Barbadian schools in globalising circumstances. Globalisation, Societies and Education 12: 211-227.

McCarthy C and Kenway J. (2014) Introduction: Understanding the rearticulations of privilege over time and space. Globalisation, Societies and Education 12: 165-176.

Ong A. (1999) Flexible Citizenship: The Cultural Logics of Transnationality, Durham, NC: Duke University Press.

Power S, Brown P, Allouch A, et al. (2013) Self, Career and Nationhood: The contrasting aspirations of British and French elite graduates. British Journal of Sociology 64: 578-596.

Reay D, Hollingworth S, Williams K, et al. (2007) 'A Darker Shade of Pale?' Whiteness, the Middle Classes and Multi-Ethnic Inner City Schooling. Sociology 41: 1041-1060.

Resnik J. (2012) Sociology of international education - an emerging field of research. International Journal in Sociology of Education 22: 291-310. 
Maxwell, C. \& Aggleton, P. (in press) Creating cosmopolitan subjects - the role of families and private schools in England. Sociology.

Rizvi F. (2005) International education and the production of cosmopolitan identities. Transnational Seminar Series. University of Illinois at Urbana-Champaign.

Rizvi F. (2014) Old elite schools, history and the construction of a new imaginary. Globalisation, Societies and Education 12: 290-308.

Rothkopf D. (2009) Superclass: The Global Power Elite and the World They Are Making, London: Abacus.

Sassen S. (2012) Cities in a world economy, London: Sage.

Savage M, Bagnall G and Longhurst B. (2005) Globalisation and Belonging, London: Sage.

Skeggs B. (2004) Class, self, culture, London: Routledge.

Snee H. (2013) Framing the Other: Cosmopolitanism and the representation of difference in overseas gap year narratives. British Journal of Sociology 64: 142-162.

Stevens ML. (2009) Creating a Class: College Admissions and the education of elites, Cambridge, MA: Harvard University Press.

van Zanten A and Maxwell C. (2015) Elite education and the State in France: Durable ties and new challenges. British Journal of Sociology of Education 36: 71-94.

Waters J. (2008) Education, Migration and Cultural Capital in the Chinese Diaspora: Transnational students between Hong Kong and Canada., New York: Cambria Press.

Weenink D. (2008) Cosmopolitanism as a form of capital. Parents preparing their children for a globalizing world. Sociology 42: 1089-1106.

Weis L and Cipollone K. (2013) 'Class work': Producing privilege and social mobility in elite US secondary schools. British Journal of Sociology of Education 34: 701-722. 